\title{
Cost-effectiveness of cognitive behavioural therapy for treatment-resistant depression: challenges and solutions conducting an economic evaluation of the long-term follow-up of the cobalt trial
}

\author{
Kirsty Garfield ${ }^{1,2^{*}}$, Laura Thomas ${ }^{1}$, Tim Peters ${ }^{1}$, Nicola Wiles ${ }^{1}$, Sandra Hollinghurst ${ }^{1}$ \\ From 3rd International Clinical Trials Methodology Conference \\ Glasgow, UK. 16-17 November 2015
}

\section{Introduction}

Most trial-based economic evaluations are restricted to the follow-up period of the trial. We present challenges faced conducting an economic evaluation of the longterm (LT) follow-up of a successful trial and describe solutions, which could inform similar studies.

\section{Methods}

An economic evaluation was conducted alongside the LT follow-up of the CoBalT trial assessing the effectiveness and cost-effectiveness of cognitive behavioural therapy (CBT) for patients with treatment resistant depression.

Challenges included: follow-up at a variable interval after randomisation date; resource use data from a questionnaire smaller in scope than the trial and available for a limited period; inconsistent availability of unit costs and missing data due to loss to follow-up. Challenges were addressed by: combining questionnaire data with information from the trial to estimate average annual values of costs over the whole follow-up period; collecting detailed health care resource use over the whole period for a sample using practice notes; using a mix of inflation-adjusted and updated unit costs; and multiple imputation to estimate missing data.

\section{Results}

The LT complete case analysis included 214 of the original 469 participants. Mean annual incremental cost to the NHS was $£ 281$; QALY gain was 0.052 . The incremental cost-effectiveness ratio was $£ 5,374$. At a threshold

University of Bristol, Bristol, UK

Full list of author information is available at the end of the article willingness-to-pay of $£ 20,000$, this represents a $92 \%$ probability of cost-effectiveness. Results remained robust in sensitivity analyses.

\section{Conclusions}

Despite methodological challenges, using all available information and a variety of modelling and imputation techniques, we were able to estimate annualised costs and effects of a CBT intervention over the long term.

\section{Authors' details}

${ }^{1}$ University of Bristol, Bristol, UK. ${ }^{2}$ Bristol Randomised Trials Collaboration, Bristol, UK.

Published: 16 November 2015

doi:10.1186/1745-6215-16-S2-P24

Cite this article as: Garfield et al:: Cost-effectiveness of cognitive

behavioural therapy for treatment-resistant depression: challenges and solutions conducting an economic evaluation of the long-term follow-up of the cobalt trial. Trials 2015 16(Suppl 2):P24.

Submit your next manuscript to BioMed Central and take full advantage of:

- Convenient online submission

- Thorough peer review

- No space constraints or color figure charges

- Immediate publication on acceptance

- Inclusion in PubMed, CAS, Scopus and Google Scholar

- Research which is freely available for redistribution 